\title{
Attitudes and practices of community pharmacists and barriers to their participation in public health activities in Yemen: mind the gap
}

Seena A. Yousuf ${ }^{1}$, Mohammed Alshakka ${ }^{2 *}$, Wafa F. S. Badulla ${ }^{3}$, Heyam Saad Ali ${ }^{4}$, P. Ravi Shankar ${ }^{5}$ and Mohamed Izham Mohamed Ibrahim ${ }^{6}$

\begin{abstract}
Background: Patients in Yemen commonly visit community pharmacies to obtain consultation or treatment for common ailments. Community pharmacists have an opportunity to optimize medication use and improve patient outcomes. This study aimed to evaluate the attitudes and practices of community pharmacists regarding their participation in public health activities and barriers to their participation in these activities.

Methods: This cross-sectional study was carried out among community pharmacists working in pharmacies located in urban areas of the Aden governorate of Yemen from March to June 2017 using a self-administered questionnaire. We selected pharmacies from a line list using proportional sampling according to the number of pharmacies in the urban areas of each district. The questionnaire contained four sections: demographic characteristics, attitudes, practices, and barriers encountered. Data were analyzed descriptively, and the Chi-square test was used for analyzing the association of variables (alpha $=0.05$ ).

Results: The questionnaire was distributed to 200 community pharmacists working in community pharmacies. Of the 200 respondents, $62 \%(n=124)$ were male. Overall, the mean age (sd) was 30.0 years (8.6) with the number of years of work experience between 2 and 9.9 years $(n=158,79 \%)$. On average, $62.3 \%$ of the pharmacists had a positive attitude toward participation in public health activities. Providing education to stop tobacco chewing, smoking, alcohol drinking and improve oral hygiene was an important activity of the community pharmacists. Blood pressure measurements (86\%, $n=172)$ and glucose tests $(45 \%, n=90)$ were commonly conducted for clients. Lack of time $(71 \%, n=142)$ and lack of teamwork $(70 \%, n=140)$ were mentioned as common barriers to participation in public health activities.

Conclusions: Community pharmacists had a positive attitude toward public health activities. Health education and routine health tests were important practices of the community pharmacists. Barriers need to be overcome to enable more active participation by community pharmacists in public health activities by consulting with all stakeholders, assessing the situation, considering alternatives and taking action.
\end{abstract}

Keywords: Community pharmacies, Cognitive services, Extended services, Health education, Health outcomes, Public health, Yemen

\footnotetext{
* Correspondence: alshakka400@gmail.com

${ }^{2}$ Section of Clinical Pharmacy, Faculty of Pharmacy, Aden University, Aden,

Yemen

Full list of author information is available at the end of the article
}

(C) The Author(s). 2019 Open Access This article is distributed under the terms of the Creative Commons Attribution 4.0 International License (http://creativecommons.org/licenses/by/4.0/), which permits unrestricted use, distribution, and reproduction in any medium, provided you give appropriate credit to the original author(s) and the source, provide a link to the Creative Commons license, and indicate if changes were made. The Creative Commons Public Domain Dedication waiver (http://creativecommons.org/publicdomain/zero/1.0/) applies to the data made available in this article, unless otherwise stated. 


\section{Background}

Yemen is a low-income country whose health system suffers from lack of basic health care, poor facilities and lack of access to essential medicines [1-3]. Since 2015, sociopolitical conflict has affected all aspects of life, including health sector activities. Among the major medicine-related problems in the country are problems with prescribing and dispensing medication, improper use of medicine by consumers, problems with adverse drug reaction monitoring, and medical error [4-6]. Many patients view pharmacists in Yemen as drug sellers who only dispense and sell medicine [4]. Especially during the ongoing crisis, pharmacists in Yemen can play a critical role in supporting and maintaining public health. Pharmacists have an obligation, as well as opportunity to improve public health [7]. In Yemen, community pharmacists are only involved in the dispensing of medicine [4]. Most community pharmacists are not yet involved in providing public health services and health promotion activities. Despite the valuable role of community pharmacists, little research has examined their extended roles and tasks, beyond just dispensing and selling medicines. In Yemen, similar to many other low- and middle-income countries (LMICs), persons without pharmacy-related academic qualifications manage pharmacies and prescribe and dispense medicine.

Pharmacists are now considered important members of health care teams involved in decisions about drug use and adverse effects [8], particularly in community and hospital pharmacies $[9,10]$. At the beginning of the twenty-first century, there were a number of calls to reform the pharmacy curricula to enable future pharmacists to meet their new roles and responsibilities [11]. These new roles necessitate improving clinical knowledge and skills toward patients [12,13] and communicating with patients and other health care workers [14, 15].

Pharmacists provide a critical service to society and interact with people from diverse backgrounds. Due to the easy access and friendly approach of pharmacists, community pharmacies are among the first place patients visit to obtain consultation or treatment for their common ailments [16]. Moreover, pharmacists have an opportunity to participate in public health strategies, assist in decision-making and support public health efforts.

Public health has been defined as "what we as a society do to assure the conditions in which people live can be healthy" [17]. In contrast to medicine, public health initiatives emphasize the prevention of disease and consider the health needs of the population as a whole [18].

Community pharmacists have a role and responsibility to optimize medication use and improve patient outcomes and quality of life. Pharmacists are expected to possess a high level of personal skills to enable them to provide a good standard of practice and care and to deal with patients as individuals and respect their dignity. In dealing with other health care professionals, pharmacists must also follow standards of professional practice and establish a good working relationship with colleagues.

Ease of access to community pharmacists makes them the first choice to obtain health care for many patients [19]. Thus, the involvement of public health pharmacists in the health care system has been expanding in the last decade [16]. Hence, it is important to adopt suitable strategies to improve the participation of community pharmacists in public health activities. These improvements can only be carried out if there is continuous evaluation of the services provided at these pharmacies. On the other hand, healthcare providers in general and pharmacists in particular face a number of obstacles to providing good quality patient care.

Community pharmacists in Yemen have an important social obligation. They should be able to reach the community and provide extended services (i.e., cognitive services) during the state crisis. To date, there is little information in Yemen on community pharmacists' level of contribution as public health practitioners. Thus, this study was carried out to explore the attitudes and practices of community pharmacists regarding their participation in public health activities and the barriers to their participation in these activities in the Aden governorate of Yemen.

\section{Methods}

Study design An observational cross-sectional study was carried out from March to June 2017 among community pharmacists. The study used a validated self-administered questionnaire.

Study site Yemen has 20 governorates subdivided into districts. The study was carried out in Aden, one of the governorates of Yemen. Aden, which is the capital city of Yemen is one of the districts in the governorate. Other districts include Seera, Al Muaala, AlTawahi, Khormakser, Al Mansoora, Alshaikh-Othman, Dar-saad, and Alburaika, covering $7000 \mathrm{~km}^{2}$ with a population of 634,710 . The study covered only the urban areas.

Study population and sampling The study population consisted of community pharmacists working at registered individually owned community pharmacies operating in the Aden governorate. Of the 468 community pharmacies on the list of pharmacies obtained from the Health Office of Aden, we estimated a sample size of 200 individuals based on a formula previously used for survey research [20]. The number of pharmacists from each district was proportional to the number of pharmacies in the district. Based on the geographic distribution of the pharmacies, we chose pharmacists using convenience 
sampling. If a pharmacist refused to participate or did not return the questionnaire within the required timeframe, we replaced the pharmacist with another from a different pharmacy in the same geographic area.

Data collection and management Data were collected using a self-administered questionnaire in the Arabic language that was developed through a review of relevant literature and expert opinion. The questionnaire had four sections (refer to Additional file 1). The first section explored demographic characteristics and practice information of the community pharmacists. The second section studied the attitudes of the community pharmacists toward public health activities and education using a five-point Likert scale; scores below the midpoint of 3 were considered to be positive responses. The 'disagree' and 'strongly disagree' responses on attitudes of community pharmacists toward public health activities were combined and calculated as the mean scores (sd) and the percentage of positive responses. As the statements were negatively worded, scores less than the midpoint of 3 indicated positive responses. The third section examined the practice (i.e., activities) of the community pharmacists using a five-point Likert scale; scores above the midpoint of 3 were considered to be positive responses. In addition, the medical tests that the community pharmacists commonly carried out in the pharmacy were investigated. The fourth section focused on barriers faced by the community pharmacists with regard to participation in public health activities.

A pilot study was performed among 40 pharmacists who were not included in the final study, and the internal consistency (i.e., Cronbach's alpha) of the questionnaire was 0.748 . The questionnaire was distributed by a researcher and trained pharmacist who instructed the community pharmacists to complete the survey within three days. The pharmacies were visited again after 3 days, and the researchers collected the completed questionnaires. The pharmacists were given another $48 \mathrm{~h}$ if the survey form still had not been completed. The head of the research team then checked the completeness of the self-administered questionnaires.

Data analysis Statistical Package for Social Sciences (SPSS) version 15 (SPSS Inc. Released 2007. SPSS for Windows, Version 15.0. Chicago, SPSS Inc.) was used for data entry and analysis. The frequency of various responses was noted. The mean (sd), frequency distribution, and percentage of the variables were calculated. The Chi-square test determined whether variables such as age, gender, years of experience, and educational level influenced the questionnaire scores at a significance level of 0.05 .

\section{Results}

The internal consistency (i.e., Cronbach's alpha) of the final questionnaire was 0.717 . The majority of the respondents were male $(n=124,62 \%)$ with an overall average age (mean $\pm \mathrm{sd}$ ) of $30.0 \pm 8.6$ years. The dominant age group was 20-29 years old $(n=132,66 \%)$, followed by the 30-39-year-old age group $(n=44,22 \%)$. With regard to the educational level of the respondents, $51 \%(n=102)$ of pharmacists had a diploma, and $49 \%$ $(n=98)$ had a bachelor's degree. Of the respondents, $87 \%$ had less than 10 years (median $(\mathrm{IQR})=5.0(2.4-7.0)$ ) of work experience. The distribution of pharmacists/pharmacies by location showed that $40 \%$ of the community pharmacists were from the Al-Mansoora district, followed by $25 \%$ from the AlShikh-Othman district (Table 1 ).

Relating to attitudes toward participation to public health activities, on average, $62.3 \%$ of the pharmacists had positive responses to statements (Table 2). The results indicated only one negative attitude response to the statement - 'Public health activities belong only to health centers' ( $3.44 \pm 1.23 ; 47 \%)$. The other statements showed that the community pharmacists were positive (reversed statements).

The Chi-square test results showed that the questionnaire scores were significantly different with regard to age $(p<0.001)$, gender $(p<0.001)$, years of experience $(p<0.001)$, and educational level $(\mathrm{p}<0.001)$ (Table 2$)$.

Community pharmacists noted that the most sought after service that they delivered was education and information related to oral health $(3.93 \pm 0.91,96 \%)$. Moreover, they also provided information on how to stop smoking cigarettes $(4.30 \pm 0.98,91 \%)$ and chamna (a form of tobacco) $(4.50 \pm 0.90,95 \%)$, chewing khat (the leaves of an Arabian shrub, which are chewed or drunk as a stimulant) $(4.14 \pm 1.02,91 \%)$, and drinking alcohol $(4.40 \pm 1.07,92 \%)$, and on immunodeficiency syndrome $(4.21 \pm 1.05,88 \%)$ and how to follow a proper nutrition regime $(4.49 \pm 0.88,90 \%)$. (Table 3$)$.

Of the community pharmacists who mentioned that they provided health-related diagnostic tests for clients, $86 \%(n=172)$ performed blood pressure measurements, $45 \%(n=90)$ conducted blood glucose tests, $17 \%(n=34)$ performed pregnancy tests, $7 \%(n=14)$ conducted blood cholesterol tests and $3 \%(n=6)$ did urine examinations. Vaccinations were provided by $3 \%(n=6)$ of the community pharmacists (Fig. 1).

With regard to participation in public health activities, $63 \%(n=126)$ of community pharmacists felt that they could contribute to educational activities related to public health, such as health advancement and disease prevention, if given proper training. Among the barriers they cited were lack of time $(71 \%, n=142)$, lack of teamwork $(70 \%, n=140)$ and lack of outside funds $(58 \%, n=116)$ (Table 4). 
Table 1 Demographic characteristics of community pharmacists and pharmacies

\begin{tabular}{|c|c|}
\hline Characteristics & Frequency (\%) \\
\hline \multicolumn{2}{|l|}{ Gender } \\
\hline Male & $124(62.0)$ \\
\hline Female & $76(38.0)$ \\
\hline \multicolumn{2}{|l|}{ Age group (years) } \\
\hline $20-29$ & $132(66.0)$ \\
\hline $30-39$ & $44(22.0)$ \\
\hline $40-49$ & $10(5.0)$ \\
\hline $50-59$ & $14(7.0)$ \\
\hline \multicolumn{2}{|l|}{ Educational level } \\
\hline Bachelor in Pharmacy (BPharm) & $98(49.0)$ \\
\hline Diploma in Pharmacy & $102(51.0)$ \\
\hline \multicolumn{2}{|l|}{ Years of experience } \\
\hline Less than 2 & $16(8.0)$ \\
\hline $2-9.9$ & $158(79.0)$ \\
\hline 10-19.9 & $8(4.0)$ \\
\hline $20 \&$ more & $18(9.0)$ \\
\hline \multicolumn{2}{|c|}{ Number of pharmacies in each directorate/district } \\
\hline Al-Buraika & $10(5.0)$ \\
\hline Al-Manssora & $80(40.0)$ \\
\hline Al-Mualaa & $10(5.0)$ \\
\hline Dar-Saad & $10(5.0)$ \\
\hline Khormaksar & $10(5.0)$ \\
\hline Seera & $20(10.0)$ \\
\hline AlShikh-Othman & $50(25.0)$ \\
\hline AlTawahi & $10(5.0)$ \\
\hline \multicolumn{2}{|l|}{ Number of clients daily } \\
\hline Less than 30 & $40(20.0)$ \\
\hline $30-<59$ & $106(53.0)$ \\
\hline $60-<89$ & $22(11.0)$ \\
\hline $90 \&$ more & $32(16.0)$ \\
\hline Total & $200(100)$ \\
\hline
\end{tabular}

\section{Discussion}

This study evaluated the attitudes and practices of community pharmacists regarding their participation in public health activities and the barriers preventing their participation in these activities in the Aden governorate of Yemen. The community pharmacists had a positive attitude to involvement in public health activities. They were engaged in educational activities related to personal life style practices, along with health monitoring tests. Barriers noted were lack of time to consult with clients and lack of teamwork with their colleagues.

Almost two-thirds of community pharmacists felt that people will accept pharmacists' participation in public
Table 2 Community pharmacists' attitudes towards public health activities

\begin{tabular}{lll}
\hline Statement & Mean (SD) & $\begin{array}{l}\text { Positive } \\
\text { responses (\%) }\end{array}$ \\
\hline $\begin{array}{l}\text { Pharmacists should not be involved } \\
\text { in public health activities }\end{array}$ & $1.51(0.99)$ & 92 \\
$\begin{array}{l}\text { People will not accept my participation } \\
\text { in public health activities }\end{array}$ & $1.98(0.83)$ & 83 \\
I am not ready to be involved with & $2.02(1.08)$ & 75 \\
public health activities. & & \\
$\begin{array}{l}\text { It is not important for pharmacists to } \\
\text { practice health promotion activities. }\end{array}$ & $2.13(1.03)$ & 72 \\
$\begin{array}{l}\text { Health education only to problems } \\
\text { related to drugs should be provided. }\end{array}$ & $2.59(1.27)$ & 66 \\
I am not interested in public health \\
$\begin{array}{l}\text { activities as it is the work of doctors } \\
\text { and nurses }\end{array}$ \\
$\begin{array}{l}\text { I don't have enough knowledge to advice } \\
\text { patients on health promotion and disease } \\
\text { prevention. }\end{array}$ & $2.23(1.01)$ & 64 \\
$\begin{array}{l}\text { Public health activities belong to } \\
\text { health centers }\end{array}$ & 63 \\
$\begin{array}{l}\text { I do not have the time to educate } \\
\text { patients on health issues. }\end{array}$ & $3.44(1.23)$ & 47 \\
$\begin{array}{l}\text { Other health workers do not allow } \\
\text { pharmacists to carry out activities } \\
\text { related to public health. }\end{array}$ & $2.83(0.95)$ & 41 \\
\hline
\end{tabular}

health activities, and they were ready to be involved with these activities. Armstrong et al. [21] stressed that community pharmacists can play an important role in public health and they need to be competent in different areas of practice. There are three domains that community pharmacists can be involved in i.e. health protection and prevention, health and social care, and health improvement [22]. Walker referred to these practices as 'pharmaceutical public health' [23]. The number of skilled and educated community pharmacists available for counseling patients about specific issues related to the prescribed medication, and reporting common adverse effects, was low according to a previous study conducted in Aden, Yemen [24].

The feedback obtained from the majority of the community pharmacists showed positive attitude toward involvement in public health activities and recognition of its vital contribution. The results of a study by Offu and coworkers was similar to our study and demonstrated positive attitude among the community pharmacists towards public health practices even though the knowledge and practice level were not satisfactory [25]. Other studies and a systematic review showed a similar situation [26-28]. Many community pharmacists were willing to be a part of public health activities, having knowledge about the importance of practicing health promotion activities and they were interested in supporting 
Table 3 Community pharmacists' public health activities

\begin{tabular}{lll}
\hline Statement & Mean (SD) & $\begin{array}{l}\text { Positive } \\
\text { responses (\%) }\end{array}$ \\
\hline Oral health & $3.93(0.91)$ & 96 \\
Education to stop Chamma & $4.50(0.90)$ & 95 \\
Education to stop alcohol drinking & $4.40(1.07)$ & 92 \\
Education to stop Khat chewing & $4.14(1.02)$ & 91 \\
Education to stop smoking & $4.30(0.98)$ & 91 \\
Education to follow healthy & $4.49(0.88)$ & 90 \\
nutrition regime & & \\
Information about acquired & $4.21(1.05)$ & 88 \\
immunodeficiency syndrome & & \\
Information about contraceptive & $3.92(0.94)$ & 82 \\
methods & & \\
Information about cancer & $3.89(1.02)$ & 81 \\
Unused or expired drugs & $3.90(1.01)$ & 76 \\
Medical instruments & $3.65(1.19)$ & 70 \\
Education to follow a healthy lifestyle & $3.73(1.04)$ & 69 \\
Weight reduction & $3.39(1.13)$ & 56 \\
Cholesterol balance & $3.24(0.99)$ & 47
\end{tabular}

public health activities as a part of the health care team. A study in Ethiopia indicated a low level of participation of community pharmacists in public health activities [29]. In this study, fourth-fifth of respondents claimed that the other health workers do not allow pharmacists to carry out public health activities. Hence, good communication and cooperation between different health care professionals should be established [30]. However, the public acceptance of the participation of community pharmacists in public
Table 4 Barriers toward involvement of community pharmacists in public health activities

\begin{tabular}{ll}
\hline Statements & $N(\%)$ \\
\hline Lack of time & $142(71.0)$ \\
Lack of the concept of teamwork & $140(70.0)$ \\
Lack of outside funds to assist pharmacists & $116(58.0)$ \\
Lack of training & $112(56.0)$ \\
Lack of financial capital to implement changes & $108(54.0)$ \\
Lack of official recognition of public health activities & $108(54.0)$ \\
Lack of the concept of public health activities & $98(49.0)$ \\
Lack of specialty and experience & $86(43.0)$ \\
\hline
\end{tabular}

health activities is perceived as positive. All these findings suggest that there is an acceptance from both the community pharmacists and patients toward changing from the traditional role of dispensing medication to more effective involvement in health care activities.

The community pharmacists felt it was important for pharmacists to practice health promotion activities. They also had a positive opinion regarding providing health education beyond drug-related issues, and believed that public health activities are not just the responsibility of doctors and nurses. They also were of the opinion that community pharmacists have enough knowledge to advice patients on health promotion and disease prevention. They claimed that they have been practicing various public health activities such as oral health; educating the clients on matters related to chamna, alcohol drinking, khat chewing, smoking, health nutrition, healthy lifestyle; providing information on immunodeficiency

\section{Services provided by the community pharmacists}

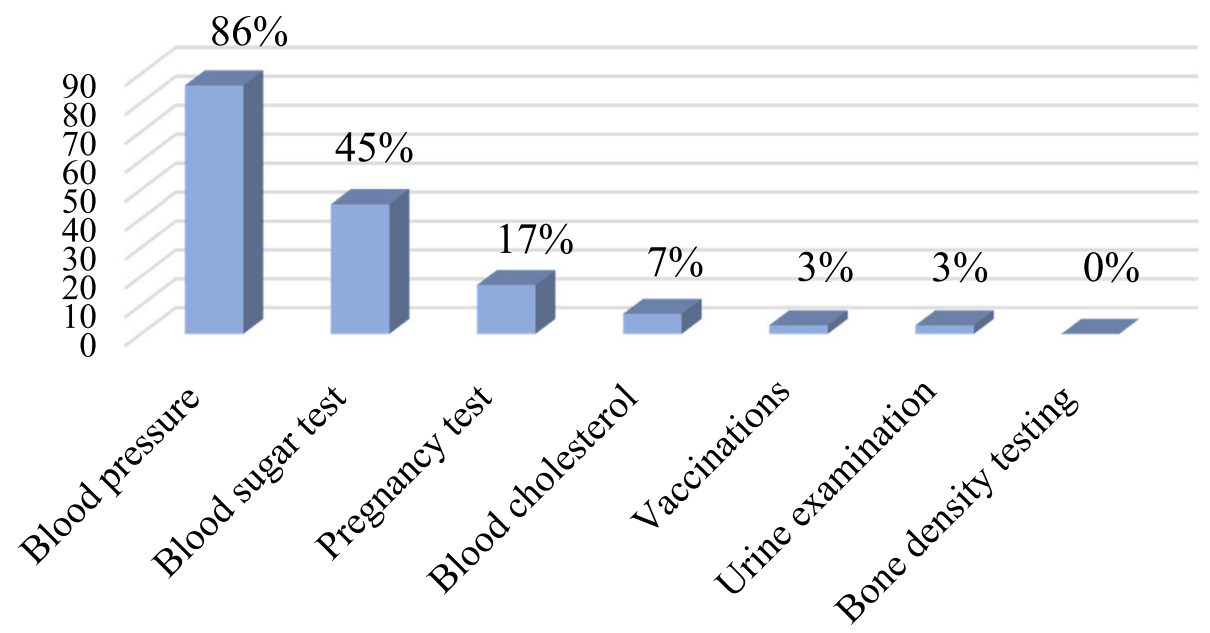

Fig. 1 Services provided by the community pharmacists 
syndrome; providing information on contraceptives, cancer drugs, matters related to expired and unused medicines, the use of medical devices, weight reduction and cholesterol. Among the medical tests commonly conducted by community pharmacists were blood pressure, glucose and pregnancy tests. The educational activities conducted by community pharmacists for their patients as part of the public health activities were consistent with the activities provided by the community pharmacists in other low- and middle-income countries [31]. Agomo et al. reported that the literature revealed that services such as smoking cessation, health promotion, provision of hormonal contraceptives and preventive activities provided by pharmacists have benefited the community [32]. Community pharmacists carried out medical tests such as blood pressure measurement and blood glucose test. By offering these screening tests, the community pharmacists may assist patients with diagnosis and therapy. The provided medical tests were similar to the services offered by community pharmacists in Dhaka, Bangladesh [31].

The community pharmacists stated several barriers hindering their involvement in public health activities. Among them were lack of time, lack of understanding of the concept of teamwork among the different healthcare professionals, lack of understanding of the concept of public health, shortage of funds and capital to implement improvements, lack of training, recognition, specialty and experience. The last part of the current study related to the obstacles and difficulties facing the community pharmacists with regard to effective contribution to public health activities. The major obstacles reported in the current survey were lack of time, and of the concept of teamwork followed by shortage of external funds and lack of official recognition of participation in public health activities. Comparable barriers have also been reported in some developing countries like Ethiopia and southeast Nigeria [29, 32]. The reported barriers can be partly overcome if there is willingness to provide free public health services rather than charging services to improve business profitability by the community pharmacists. In addition, the healthcare professionals must embrace the concept of collaborative care i.e. teamwork between physician and pharmacist. Public health activities can be performed and enhanced by working together. There are key areas such as interprofessional collaborative care, working with and for communities that community pharmacists should consider as initial steps for their involvement in public health activities [33].

Even though the study provided some insights on the pharmacy public health activities in Yemen, it has a few limitations. The study was conducted with a small sample and only part of the registered community pharmacists; thus, the findings may not represent the actual perspective of community pharmacists in the entire country. Furthermore, the study was only conducted in one of the governorates of Yemen due to the war and safety issue. Thirdly, self-perception of community pharmacists i.e. relying on self-reported information may contribute to bias.

The authors wish to recommend the following actions. First, from the research angle, future studies need to be carried out on a larger geographical area and sample size, as well as using different methods such as simulated patient method. There should be more researches that study the current situation, identify possible problems and suggest solutions. Secondly, from the policy and practice viewpoints, the basic core services provided by pharmacists to the public should be strengthened especially when state is at crisis [34, 35]. In order to improve the provision of pharmaceutical care, Farris and Schopflocher recommended accessibility of qualified and cooperative staff for dispensing activities [36]. Pharmacists need to be well-trained, competent and confident in order to have positive outcome [26]. Offering specific training is a necessary requirement to boost community pharmacists' involvement in the health care services. Community pharmacists should have time to participate in continuing professional education to upgrade the level of the provided services. However, the quality and impact of the services on the individuals and public are not known; thus, it need to be investigated. Evaluation of the community pharmacist's contribution must be carried out to strengthen their contribution to public health activities. Various stakeholders should collaborate for improving the services and enhancing the competency of the community pharmacists. Community pharmacists must be accepted as an important member of the health care team. Policymakers should develop appropriate policies to improve the involvement of community pharmacists in public health activities in Yemen.

\section{Conclusions}

In Yemen, as in many LMICs, the role and contribution of community pharmacists is not well appreciated even though they are located in a unique position. This study highlighted the gaps with regard to community pharmacists' roles, and contributions to public health services, especially during the state crisis. Health facilities in Yemen are badly affected and in need of humanitarian support. Thus, community pharmacists need to be increasingly involved in public health activities. The study concluded that the community pharmacists had positive attitudes toward public health activities, had been practicing public health activities to a certain extent, but had identified barriers that prevented their effective contribution as public health practitioners. 


\section{Additional file}

Additional file 1: Questionnaire on attitudes, practices and barriers of community pharmacists to public health activities in Yemen. (PDF 180 $\mathrm{kb})$

\section{Abbreviation \\ LMICs: Low- and Middle-Income Countries}

\section{Acknowledgements}

The authors are very grateful for the participation of pharmacists in the community pharmacies in Aden governorate, Yemen. We also thank Dorothy $\mathrm{L}$ Southern for her critical review of this manuscript and support with scientific writing

\section{Funding}

No funding was obtained for the study.

\section{Availability of data and materials}

The datasets used and/or analyzed during the current study are available from the link https://figshare.com/articles/Attitudes_and_Practices_of_ Community_Pharmacists_and_Barriers_to_their_Participation_in_Public_ Health_Activities_in_Yemen/7983062

\section{Authors' contributions}

SAY and MA conceived of the presented idea with help from WFSB, HAS, PRS and MIMI. SAY, MA, WFSB, and HAS contributed to the design and implementation of the research, to the analysis of the results and to the writing of the manuscript. PRS and MIMI contributed to the literature survey and contributed to writing the manuscript. All authors discussed the results, contributed to the final manuscript, provide final approval of the version to be published; and agreement to be accountable for all aspects of the work in ensuring that questions related to the accuracy or integrity of any part of the work are appropriately investigated and resolved. MA, PRS and MIMI were mainly involved in revising the manuscript for critical intellectual content

\section{Ethics approval and consent to participate}

The study was approved by the Committee of Research and Postgraduate Studies, Faculty of Medicine and Health Science, Aden University (i.e. ethics committee for all research in health faculties in Aden). The ethics committee approved the procedure for verbal consent. Verbal consent was attained from all participants after explaining the purposes, significance and advantages of the research by the trained data collector and through a covering letter provided to each respondent. They were assured that all the gathered information would be kept private and used only for the purpose of the study. They were also informed that they had the right to withdraw from the study at any time.

\section{Consent for publication}

Not applicable.

\section{Competing interests}

The authors declare that they have no competing interests.

\section{Publisher's Note}

Springer Nature remains neutral with regard to jurisdictional claims in published maps and institutional affiliations.

\section{Author details}

${ }^{1}$ Social Medicine and Public Health Department, Faculty of Medicine and Health Sciences, Aden University, Aden, Yemen. ${ }^{2}$ Section of Clinical Pharmacy, Faculty of Pharmacy, Aden University, Aden, Yemen. ${ }^{3}$ Department of Analytical Chemistry, Faculty of Pharmacy, Aden University, Aden, Yemen. ${ }^{4}$ Department of Pharmaceutics, Dubai Pharmacy College, Dubai, United Arab Emirates. ${ }^{5}$ Department of Pharmacology, Health City University, Gros Islet, Saint Lucia. ${ }^{6}$ Department of Clinical Pharmacy and Practice, College of Pharmacy, Qatar University, Doha, Qatar.
Received: 7 December 2018 Accepted: 29 April 2019

Published online: 14 May 2019

\section{References}

1. International Rescue Committee. IRC report: Failed public health system 'quiet killer' in Yemen. 2018. https://www.rescue.org/press-release/irc-reportfailed-public-health-system-quiet-killer-yemen. Accessed 15 March, 2019.

2. International Committee of the Red Cross. Health crisis in Yemen. 2017. https://www.icrc.org/en/where-we-work/middle-east/yemen/health-crisisyemen. Accessed 15 March, 2019.

3. AL-Tamimi SK, Hassali MAA, Alrasheedy AA. Challenges to generic medicines utilization in Yemeni healthcare system. Generics and Biosimilars Initiative J (GaBI J) 2013;2(2):63-64. https://doi.org/10.5639/gabij.2013.0202. 017. http://gabi-journal.net/challenges-to-generic-medicines-utilization-inyemeni-healthcare-system.html. Accessed 15 March, 2019.

4. Al-Worafi Y. Pharmacy practice and its challenges in Yemen. Australas Med J. 2014;7:17-23. https://doi.org/10.4066/AMJ.2014.1890.

5. Al-Tamimi S, Hassali MAA, Shafie A, Alrasheedy A. Substandard medications in Yemen. Australas Med J. 2015;8:100-2.

6. Alshakka M, Saeed GMA, Ali H, Prajapati SK, Ibrahim MI. Adverse drug reactions and medication errors in tertiary care hospitals: a quantitative insight in Aden, Yemen. J Young Pharm. 2019;11(1):82-7.

7. ASHP Statement on the Role of Health-System Pharmacists in. Public Health Am J Health-Syst Pharm. 2008;65:462.

8. Hanlon JT, Weinberger M, Samsa GP, Schmader KE, Uttech KM, Lewis IK, et al. A randomized, controlled trial of a clinical pharmacist intervention to improve inappropriate prescribing in elderly outpatients with polypharmacy. Am J Med. 1996;100:428-37.

9. Berger BA. Communication skills for pharmacists: building relationships, improving patient care. Washington DC: American Pharmacists Association; 2005

10. Hepler CD. Clinical pharmacy, pharmaceutical care, and the quality of drug therapy. Pharmacotherapy. 2004;24:1491-8.

11. Chiquette $E$, Amato M, Bussey H. ACCP white paper a vision of pharmacy's future roles, responsibilities, and manpower needs in the United States. Pharmacotherapy. 2000;20:991-1020.

12. Adamcik BA, Ransford HE, Oppenheimer PR, Brown JF, Eagan PA, Weissman FG. New clinical roles for pharmacists: a study of role expansion. Soc Sci Med. 1986;23:1187-200

13. Worley MM, Schommer JC, Brown LM, Hadsall RS, Ranelli PL, Stratton TP, et al. Pharmacists' and patients' roles in the pharmacist-patient relationship: are pharmacists and patients reading from the same relationship script? Res Soc Adm Pharm. 2007;3:47-69.

14. Hargie OD, Morrow NC, Woodman C. Pharmacists' evaluation of key communication skills in practice. Patient Educ Couns. 2000;39:61-70.

15. Lambert BL. Face and politeness in pharmacist-physician interaction. Soc Sci Med. 1996:43:1189-98

16. Mohamed Izham Ml. Chapter 18. Assessment of Medication Dispensing and Extended Community Pharmacy Services. In: Izham Mohamed M, Ibrahim AIW, Din Babar Z-U, editors. Social and Administrative Aspects of Pharmacy in Low- and Middle-Income Countries: Present Challenges and Future Solutions. Washington DC: Elsevier: Academic Press; 2018. p. 295-309.

17. Institute of Medicine (US) Committee for the Study of the Future of Public Health. The Future of Public Health. Washington (DC): National Academies Press (US); 1988. Available from: https://www.ncbi.nlm.nih.gov/books/ NBK218218/. https://doi.org/10.17226/1091. Accessed 10 Jan 2019

18. ERIC. Higher education for public health. New York: Milbank Memoria Fund; 1976

19. Ludwig-Boltzmann-Institute for sociology of health and medicine. Health promotion in general practice and community pharmacy - conclusions and proposals from a European project, 2002.

20. Survey monkey. https://help.surveymonkey.com/articles/en_US/kb/Howmany-respondents-do-I-need. Accessed 15 December, 2018.

21. Armstrong M, Lewis $\mathrm{R}$, Blenkinsopp A, Anderson C. The contribution of community pharmacy to improving the public's healthReport 3: an overview of evidence-base from 1990-2002 and recommendations for action. London, UK: Pharmacy health link and the Royal Pharmaceutical Society of Great Britain; 2005.

22. Faculty of Public Health. Good public health practice framework. 2016. https://www.fph.org.uk/media/1304/good-public-health-practiceframework_-2016_final.pdf. Accessed 15 Feb 2019. 
23. Walker R. Pharmaceutical public health: the end of pharmaceutical care? Pharm J. 2000;264:340.

24. Alshakka M, Abdorabbo A, Basaleem H, Jha N, Alshammari T, Shankar PR. Knowledge, attitude beliefs and practices of community pharmacy dispensers in Aden, Yemen towards adverse drug reaction reporting. World J Pharm Sci. 2015;3(10):2111-8.

25. Offu O, Anetoh M, Okonta M, Ekwunife O. Engaging Nigerian community pharmacists in public health programs: assessment of their knowledge, attitude and practice in Enugu Metropolis. J Pharm Policy Pract. 2015;8:27. https://doi.org/10.1186/s40545-015-0048-0.

26. Eades C, Ferguson J, O'Carroll R. Public health in community pharmacy: a systematic review of pharmacist and consumer views. BMC Public Health. 2011;11(1):582.

27. Mohamed SS, Mahmoud AA, Ali AA. Involvement of Sudanese community pharmacists in public health activities. Int I Clin Pharm 2013;35(3):393-400. https://doi.org/10.1007/s11096-012-9745-9. Accessed date: 10 February, 2019.

28. Laliberte MC, Perreault S, Damestoy N, Lalonde L. Ideal and actual involvement of community pharmacists in health promotion and prevention: a cross-sectional study in Quebec, Canada. BMC Public Health. 2012;12:192. https://doi.org/10.1186/1471-2458-12-192 PMID: 22420693. Accessed date: 10 January, 2019.

29. Erku DA, Mersha AG. Involvement of community pharmacists in public health priorities: a multi-center descriptive survey in Ethiopia, PLoS One 2017; 12(7): e0180943. https://doi.org/10.1371/journal.pone.0180943. Accessed date: 10 November, 2018

30. Albanese NP, Rouse MJ. Council on credentialing in pharmacy. 2010. Scope of contemporary pharmacy practice: roles, responsibilities, and functions of pharmacists and pharmacy technicians. J Am Pharm Assoc. 2010;50:e35-69.

31. Rakib A, Sarwar MS, Zannah S, Khanum S, Rashid M. A survey of the role of community pharmacists in Dhaka city, Bangladesh. Bangladesh Pharm J. 2015;18(2):137-41. https://doi.org/10.3329/bpj.v18i2 24312. Accessed date: 10 November, 2018.

32. Agomo C, Udoh A, Kpokiri E, Osuku-Opio J. Community pharmacists' contribution to public health: assessing the global evidence base. Pharm J Issue :Clin Pharm, 2018; 10 (4). https://www.pharmaceutical-journal.com/ research/review-article/community-pharmacists-contribution-to-publichealth-assessing-the-global-evidence-base/20204556.article. Accessed date: 18 February, 2019.

33. Ogbonna BO, Ezenduka CC, Soni JS, Oparah AC. Limitations to the dynamics of pharmaceutical care practice among community pharmacists in Enugu urban, Southeast Nigeria. Integrated Pharm Res Pract. 2015:4:49-55.

34. WHO. Health system in Yemen close to collapse. Bull World Health Organ 2015;93:670-1. https://doi.org/10.2471/BLT.15.021015.

35. WHO. Health Situation in Yemen and WHO Response. Yemen situation reports. https://www.who.int/hac/crises/yem/sitreps/en/ Accessed date: 22 February, 2019.

36. Farris KB, Schopflocher DP. Between intention and behavior: an application of community pharmacists' assessment of pharmaceutical care. Soc Sci Med. 1999:49:55-6.

Ready to submit your research? Choose BMC and benefit from:

- fast, convenient online submission

- thorough peer review by experienced researchers in your field

- rapid publication on acceptance

- support for research data, including large and complex data types

- gold Open Access which fosters wider collaboration and increased citations

- maximum visibility for your research: over $100 \mathrm{M}$ website views per year

At BMC, research is always in progress.

Learn more biomedcentral.com/submissions 